\title{
Acceptability of remote prescribing and postal delivery services for contraceptive pills and treatment of uncomplicated Chlamydia trachomatis
}

\author{
Tom Nadarzynski (D) , ${ }^{1}$ Ynez Symonds, ${ }^{2}$ Robert Carroll, ${ }^{3}$ Jo Gibbs, ${ }^{4}$ \\ Sally Kidsley, ${ }^{2}$ Cynthia Ann Graham (i) ${ }^{5}$
}

- Additional material is published online only. To view please visit the journal online (http://dx.doi.org/10.1136/ bmjsrh-2020-200687).

${ }^{1}$ University of Westminster, London, UK

${ }^{2}$ Solent NHS Trust, Southampton, UK

${ }^{3}$ Hampshire County Council, Winchester, UK

${ }^{4}$ University College London, London, UK

${ }^{5}$ Univ Southampton,

Southampton, UK

\section{Correspondence to}

Dr Tom Nadarzynski, University of Westminster, London, UK; t. nadarzynski@westminster.ac.uk

Received 28 April 2020 Revised 23 September 2020 Accepted 29 October 2020 Published Online First 19 November 2020

\section{D) Check for updates}

(c) Author(s) (or their employer(s)) 2021. No commercial re-use. See rights and permissions. Published by BMJ.

To cite: Nadarzynski T,

Symonds Y, Carroll R, et al. BMJ Sex Reprod Health

2021:47:185-192.

\section{ABSTRACT}

Objectives The digitalisation of sexual and reproductive health $(\mathrm{SRH})$ services offers valuable opportunities to deliver contraceptive pills and chlamydia treatment by post. We aimed to examine the acceptability of remote prescribing and 'medication-by-post' in SRH.

Study design An online survey assessing attitudes towards remote management was distributed in three UK SRH clinics and via an integrated sexually transmitted infection (STI) postal self-sampling service. Logistic regressions were performed to identify potential correlates. Results There were 1281 participants (74\% female and $49 \%<25$ years old). Some $8 \%$ of participants reported having received medication via post and $83 \%$ were willing to receive chlamydia treatment and contraceptive pills by post. Lower acceptability was observed among participants who were: $>45$ years old (OR 0.43 (95\% Cl 0.23-0.81)), screened for STIs less than once annually (OR $0.63(0.42-0.93))$, concerned about confidentiality (OR 0.21 (0.90-0.50)), concerned about absence during delivery (OR 0.09 (0.02-0.32)) or unwilling to provide blood pressure readings (OR $0.22(0.04-0.97))$. Higher acceptability was observed among participants who reported: previously receiving medication by post (OR 4.63 (1.44-14.8)), preference for home delivery over clinic collection (OR 24.1 (11.1-51.9)), preference for home STI testing (OR 10.3 (6.16-17.4)), ability to communicate with health advisors (OR 4.01 (1.03-15.6)) and willingness to: register their real name (OR 3.09 (1.43-10.6)), complete online health questionnaires (OR 3.09 (1.43-10.6)) and use generic contraceptive pills (OR 2.88 (1.21-6.83)). Conclusions Postal treatment and entering information online to allow remote prescribing

\section{Key messages}

- The majority (83\%) of sexual health service users would be willing to receive contraceptive pills and chlamydia treatment via post, while one in five would prefer to receive medication directly from the doctor.

- Remote prescribing, postal delivery (medication-by-post) and click-andcollect services are highly acceptable in sexual and reproductive health.

- Those aged over 45 years, first time or infrequent service attenders, and those who do not use online health services and are concerned about their confidentiality were less likely to accept remote prescribing.

were acceptable methods for SRH services and should be considered alongside medication collection in pharmacies. These methods could be particularly useful for patients facing barriers in accessing SRH. The cost-effectiveness and implementation of these novel methods of service delivery should be further investigated.

\section{INTRODUCTION}

Every day, about 1 million people acquire a sexually transmitted infection (STI), worldwide. ${ }^{1}$ In England, around 450000 new STIs are diagnosed every year and individuals aged 16-24 years old account for $50 \%$ of new diagnoses. ${ }^{2}$ The estimated costs of STI treatments equate to $£ 620$ million per year. ${ }^{3}$ Gay, bisexual and other men who have sex with men 
(MSM), as well as Black Asian and minority ethnic (BAME) individuals, are the most affected. ${ }^{2}$

Chlamydia trachomatis is the most common bacterial STI in North America and Europe. ${ }^{4}$ If left untreated, chlamydia can cause pelvic inflammatory disease, tubal infertility and ectopic pregnancy in women, as well as epididymal-orchitis in men and, less frequently, sexually acquired reactive arthritis in both genders. ${ }^{5}$ The UK introduced the National Chlamydia Screening Programme (NCSP) in 2003 to improve detection, decrease transmission rates and reduce the associated morbidities. ${ }^{6}$ There has been a significant shift towards providing online sexual and reproductive health services (SRHS), including the utilisation of self-sampling/self-testing kits, which is particularly pertinent to 15-24-year-old women in whom chlamydia is most prevalent. ${ }^{7}$ As STIs continue to be a major public health concern, policymakers emphasise the need for optimal and cost-effective methods for increasing screening and treatment uptake. ${ }^{8}$ Young women are also at an increased risk of unplanned pregnancies, thus the provision of contraception services is a cost-effective public health intervention. In the UK, $45 \%$ of pregnancies were unplanned in women aged 16-19 years. $^{9}$ As a significant proportion of women face barriers to healthcare access, individual, social and service delivery considerations need to be addressed to reduce these barriers and increase the cost-effectiveness and efficiency of SRHS.

Digitalisation offers solutions to service delivery aiding standard care. It has been driven by the need to manage demand in an increasing austere financial environment, to increase access, equity and reduce the burden on overstretched face-to-face services in what is hoped to be a cost-effective manner. Research has demonstrated that women benefit from digital sex education and counselling around contraceptive choices and STI screening. ${ }^{10} 11$ Online services are feasible, safe and effective in the management of patients with chlamydia and other STIs. ${ }^{12}$ The proportion of chlamydia tests that are provided via online postal self-sampling services has rapidly increased, with $17 \%$ of all chlamydia tests in 15-24-year-olds in 2018 being accessed online in the UK. ${ }^{2}$ This has also been accelerated during the COVID-19 pandemic, where services had to rapidly switch to online delivery. Users express positive attitudes to online services that are convenient, fast, secure and linked with pharmacies or helplines. ${ }^{13}$ Pathway frameworks offer a comprehensive structure of e-health services in sexual and reproductive medicine as a powerful tool in public health and clinical management. ${ }^{14}$ Standardised digital history-taking tools, which can be used in both face-toface and remote clinical settings, have the potential to improve the quality of drug prescription and patient safety if users are willing to provide the necessary clinical information.
Solent SRHS have provided online postal selfsampling to the Hampshire (UK) community since 2015. The service considered remote consultations and provision of contraception and chlamydia treatment via postal delivery. Before introducing these services, the acceptability of remote management in the population needs to be established to identify barriers to effective implementation. We aimed to assess the acceptability and preferences for remote prescribing and delivery of chlamydia treatment and contraception by post.

\section{METHODS \\ Design}

This was an exploratory, cross-sectional survey focusing on service users' willingness to input clinical information online and receive chlamydia treatment and contraceptive pills delivered by post. The survey was approved as a service evaluation and development by Solent NHS Trust Clinical Governance (Ref. SE-271).

\section{Participants and data collection}

Between May and August 2018, we conducted a crosssectional survey exploring potential 'mediation-bypost' services for Solent NHS Trust SRHS. We recruited participants above the age of 16 years accessing services within Hampshire, UK. The survey was designed after consultations with service users about the development of online services. Views were gathered to formulate this questionnaire available in both pencil-and-paper and digital formats. Eight hundred paper surveys were distributed in three sexual health clinics. Service users were encouraged to complete the anonymous questionnaire while registering for their clinical appointment, with completion indicating their consent. Completed surveys were returned to the reception in an envelope and placed in a secure location. An additional 600 surveys were sent to those who requested for an online STI self-sampling kit via the SRHS website ( www.letstalkabout.nhs.uk). Individuals were then asked to return the completed survey in an envelope to the laboratory which processed the samples. Also, a web link to an online survey was advertised on the SRHS website and Twitter for additional responses. We were unable to calculate the overall response rate as there was no record of how many questionnaires were accessed online; nevertheless, 866 paper surveys were completed.

\section{Measurement}

The survey consisted of 32 questions (see online supplemental appendix 1), including demographic variables such as age, gender identity, ethnicity, sexual orientation, education, whether participants were registered with a general practitioner (GP), and any past STI diagnoses. Participants were asked about their preferred method for, and frequency of, STI screening and whether they had previously collected any 
medication via post or at a pharmacy with the options 'Delivered at home', 'Given by a doctor' or 'Collected at my pharmacy'.

Two outcome variables measured the acceptability of postal treatment services: (i) the willingness to receive chlamydia treatment (antibiotics) by post and (ii) the willingness to receive contraceptive pills by post, both with options 'Yes', 'No' and 'Not sure' (Question: "Would you be willing to receive medication (antibiotic) to treat chlamydia by post?"). Other questions assessed the most preferred methods for receiving medication and the concerns about confidentiality in receiving them by post. The acceptability of remote prescribing was assessed by asking about willingness: to be contacted by a health advisor, to completing an online questionnaire, to disclosing pre-existing medical conditions, to providing a blood pressure reading, to accepting generic (non-branded) medication and to registering their real name and contact details before the order was finalised. Specific preferences for a tracked delivery of the medication, a mobile telephone text message with the status of the order and the need to discuss the side effects and dosage with a pharmacist were assessed to inform the development of the service. Also, an expected arrival delivery time and the time to contact the clinic in case of misplaced delivery were assessed. The questions relating to the contraceptive pill were only directed to women.

\section{Patient and public involvement}

Patients were not directly involved in the design, recruitment and the conduct of the survey. Posters were disseminated in the waiting areas outlining the results of the study.

\section{Data analysis}

The variables were either categorical or ordinal. Descriptive statistics were performed to identify the percentage of responses using IBM SPSS software version 24. All variables were then dichotomised (ie, 'Yes' and 'No/not sure'; see table 1). Twenty-one simple logistic regressions with a single categorical predictor were performed to identify potential correlates of acceptability of the two outcome variables and calculate odds ratios (ORs) and 95\% confidence intervals $(95 \%$ CIs) to determine their magnitude. No modelling was used to perform regressions due to the explorative nature of the analysis.

\section{RESULTS}

In total, 1281 service users completed the survey, with about half $(49 \%)$ under the age of 25 years (table 2). The majority (74\%) identified as female, White (91\%), heterosexual or straight $(86 \%)$, and having a college or university education (78\%). Almost all (95\%) were registered with GP services and 40\% reported being diagnosed with an STI in the past. While half of the sample reported STI screening once per year or more often, for $20 \%$ of participants the survey testing was the first time they had been screened. Nearly half (48\%) stated that remote STI self-sampling, using an online testing kit, was their preferred method of STI screening.

While the majority (87\%) had collected medication at a pharmacy, only $8 \%$ reported ever receiving medication by post. In general, most participants preferred to either be given the medication by a doctor $(20 \%)$ or collect it at a pharmacy (34\%). However, in terms of receiving chlamydia treatment and contraceptive pills, many $(45 \%)$ chose home delivery as their preferred method. When asked directly, around $83 \%$ of participants were willing to receive antibiotics and contraceptive pills by post.

The assessment of preferences for remote prescribing showed that most participants reported their willingness to complete an online questionnaire (78\%), register their real name and contact details (85\%), disclose pre-existing conditions (89\%) and speak to a health advisor on the telephone (85\%) before the finalisation of the medication order. Only $27 \%$ reported a preference for a consultation about dosage and side effects with a pharmacist. Regarding contraception for women, $81 \%$ would be willing to provide blood pressure readings and $67 \%$ would accept receiving a generic version of the contraceptive pill.

The assessment of preferences for the 'medication by post' method showed that most participants (76\%) were not concerned about confidentiality, but $44 \%$ would be concerned about the medication delivery if they were away from home. Only 35\% endorsed a preference for signed tracked delivery of medication. The majority $(83 \%)$ would prefer to receive a mobile telephone update about their delivery and most participants (86\%) thought that delivery within three working days was appropriate, although a substantial proportion indicated 'next day delivery' as their preferred option for chlamydia treatment (43\%) and contraception (37\%). While $48 \%$ of the sample would wait 2-3 days to contact the clinic if the medication was not delivered, about $36 \%$ would wait only 1 day. Sexual health clinics were perceived as the preferred source of advice on the medication by post.

The highest willingness (99\%) to use remote services for chlamydia treatment was observed among participants who showed strong preferences for 'home delivery methods' of medication; the lowest willingness (41\%) was reported by the participants who would not register their real name for the medication order. Lower acceptability of chlamydia treatment by post was observed among participants who were: above the age of 45 years, screened for STIs less than once a year, concerned about their confidentiality, concerned about the delivery during their absence, and those not willing to provide their blood pressure readings. Higher acceptability was observed among participants who had received medication by post in the past, 
Table 1 Correlates of the willingness to receive medication by post

\begin{tabular}{|c|c|c|}
\hline & $\begin{array}{l}\text { Those 'willing' to receive chlamydia treatment } \\
\text { by post }\end{array}$ & $\begin{array}{l}\text { Those 'willing' to receive } \\
\text { contraceptive pills by post }\end{array}$ \\
\hline Variable & $\%$, OR $(95 \% \mathrm{Cl})$ & $\%$, OR $(95 \% \mathrm{Cl})$ \\
\hline \multicolumn{3}{|l|}{ Age (years) } \\
\hline$<45$ & $88.0 \%, 1.00$ (ref) & $84.9 \%, 1.00$ (ref) \\
\hline $45+$ & $76.3 \%, 0.43(0.23-0.81)^{*}$ & $56.8 \%, 0.19(0.09-0.41)^{*}$ \\
\hline \multicolumn{3}{|l|}{ Gender } \\
\hline Male & $81.1 \%, 1.00$ (ref) & \\
\hline Female & $88.8 \%, 1.48(0.96-2.29)$ & 0 \\
\hline \multicolumn{3}{|l|}{ Ethnicity } \\
\hline White & $87.2 \%, 1.00$ (ref) & $83.7 \%, 1.00$ (ref) \\
\hline Ethnic minority (non-White) & $84.1 \%, 0.78(0.41-1.49)$ & $78.6 \%, 0.87(0.42-1.80)$ \\
\hline \multicolumn{3}{|l|}{ Sexual orientation } \\
\hline Heterosexual & $87.3 \%, 1.00$ (ref) & $83.9 \%, 1.00$ (ref) \\
\hline Sexual minority & $88.1 \%, 1.09(0.60-2.00)$ & $78.2 \%, 0.77(0.38-1.58)$ \\
\hline \multicolumn{3}{|l|}{ Education } \\
\hline High school or below & $89.1 \%, 1.00$ (ref) & $83.9 \%, 1.26(0.75-2.10)$ \\
\hline College and university degree & $86.6 \%, 0.73(0.42-1.26)$ & $84.0 \%, 1.00$ (ref) \\
\hline \multicolumn{3}{|l|}{ Registered with a GP } \\
\hline Yes & $87.2 \%, 1.00$ (ref) & $83.3 \%, 1.00$ (ref) \\
\hline No & $77.4 \%, 0.53(0.19-1.48)$ & $69.6 \%, 0.57(0.15-2.06)$ \\
\hline \multicolumn{3}{|l|}{ Past STI infection } \\
\hline Yes & $88.4 \%, 1.00$ (ref) & $85.9 \%, 1.40(0.93-2.11)$ \\
\hline No & $86.1 \%, 0.75(0.50-1.13)$ & $82.5 \%, 1.00$ (ref) \\
\hline \multicolumn{3}{|l|}{ Ever collected medication at the pharmacy } \\
\hline Yes & $87.6 \%, 1.37(0.84-2.22)$ & $84.3 \%, 2.04(1.20-3.47)^{*}$ \\
\hline No & $83.7 \%, 1.00$ (ref) & $75.8 \%, 1.00$ (ref) \\
\hline \multicolumn{3}{|l|}{ Ever received medication via post } \\
\hline Yes & $96.7 \%, 4.63(1.44-14.8)^{*}$ & $85.3 \%, 1.56(0.66-3.73)$ \\
\hline No & $86.2 \%, 1.00$ (ref) & $83.0 \%, 1.00$ (ref) \\
\hline \multicolumn{3}{|l|}{ Frequency of STI screening } \\
\hline First time or less than once a year & $83.1 \%, 0.63(0.42-0.93)^{*}$ & $80.7 \%, 0.77(0.51-1.16)$ \\
\hline Once a year or more often & $91.0 \%, 1.00$ (ref) & $86.3 \%, 1.00$ (ref) \\
\hline \multicolumn{3}{|l|}{ Preferred method of STI screening } \\
\hline Online (home) testing & $97.1 \%, 10.3(6.16-17.4)^{*}$ & $88.1 \%, 1.63(1.05-2.55)^{*}$ \\
\hline In-clinic (GP or sexual health) & $76.7 \%, 1.00$ (ref) & $78.6 \%, 1.00$ (ref) \\
\hline \multicolumn{3}{|l|}{ Preference for receiving medication (general) } \\
\hline Delivered to home & $98.8 \%, 24.1(11.1-51.9)^{*}$ & $89.8 \%, 2.30(1.44-2.55)$ \\
\hline Collected from a pharmacy or a doctor & $76.7 \%, 1.00$ (ref) & $77.7 \%, 1.00$ (ref) \\
\hline \multicolumn{3}{|l|}{ Concerned about confidentiality } \\
\hline Yes & $60.6 \%, 0.21(0.90-0.50)^{*}$ & $67.8 \%, 0.61(0.25-1.44)$ \\
\hline No & $94.6 \%, 1.00$ (ref) & $88.4 \%, 1.00$ (ref) \\
\hline \multicolumn{3}{|l|}{ Concerned about delivery if absent at home } \\
\hline Yes & $75.2 \%, 0.09(0.02-0.32)^{*}$ & $78.3 \%, 0.83(0.36-1.89)$ \\
\hline No & $95.6 \%, 1.00$ (ref) & $87.3 \%, 1.00$ (ref) \\
\hline
\end{tabular}


Table 1 Continued

\begin{tabular}{|c|c|c|}
\hline \multirow[b]{2}{*}{ Variable } & \multirow{2}{*}{$\begin{array}{l}\text { Those 'willing' to receive chlamydia treatment } \\
\text { by post } \\
\%, \text { OR }(95 \% \mathrm{Cl})\end{array}$} & \multirow{2}{*}{$\begin{array}{l}\text { Those 'willing' to receive } \\
\text { contraceptive pills by post } \\
\%, \text { OR }(95 \% \mathrm{Cl})\end{array}$} \\
\hline & & \\
\hline Yes & $91.9 \%, 4.01(1.03-15.6)^{*}$ & $85.5 \%, 1.68(0.49-5.74)$ \\
\hline No & $54.5 \%, 1.00$ (ref) & $60.6 \%, 1.00$ (ref) \\
\hline \multicolumn{3}{|c|}{ Willingness to disclose pre-existing conditions } \\
\hline Yes & $91.0 \%, 2.87(0.79-10.4)$ & $85.9 \%, 1.00$ (ref) \\
\hline No & $51.4 \%, 1.00$ (ref) & $55.3 \%, 0.35(0.13-2.05)$ \\
\hline \multicolumn{3}{|c|}{ Willingness to register a real name for the order } \\
\hline Yes & $91.9 \%, 5.65(1.76-18.1)^{*}$ & $87.7 \%, 2.00(0.58-6.86)$ \\
\hline No & $41.2 \%, 1.00$ (ref) & $47.1 \%, 1.00$ (ref) \\
\hline \multicolumn{3}{|c|}{ Willingness to fill in an online questionnaire about health prior to order } \\
\hline Yes & $94.5 \%, 3.09(1.43-10.6)^{*}$ & $88.8 \%, 3.67(1.45-9.27)^{*}$ \\
\hline No & $54.1 \%, 1.00$ (ref) & $60.9 \%, 1.00$ (ref) \\
\hline \multicolumn{3}{|c|}{ Willingness to provide blood pressure reading } \\
\hline Yes & $89.7 \%, 1.00$ (ref) & $82.2 \%, 2.08(0.83-5.22)$ \\
\hline No & $80.1 \%, 0.20(0.04-0.97)^{*}$ & $56.2 \%, 1.00$ (ref) \\
\hline \multicolumn{3}{|c|}{ Willingness to receive generic (non-branded) medication } \\
\hline Yes & $93.9 \%, 2.88(1.21-6.83)^{*}$ & $97.5 \%, 35.8(15.8-81.3)^{*}$ \\
\hline No & $71.9 \%, 1.00$ (ref) & $44.1 \%, 1.00$ (ref) \\
\hline \multicolumn{3}{|c|}{ Preference for a consultation with a pharmacist to discuss side effects and dosage } \\
\hline Yes & $78.2 \%, 0.52(0.23-1.16)$ & $75.0 \%, 0.34(0.16-0.73)^{*}$ \\
\hline No & $90.3 \%, 1.00$ (ref) & $86.1 \%, 1.00$ (ref) \\
\hline
\end{tabular}

preferred the home delivery method for medication, preferred online/home testing for STIs, were willing to speak with a health advisor, register their real name, complete online health questionnaires, and use generic medication.

The highest willingness (97\%) to use remote services for contraceptive pills was observed among women who were willing to use generic, non-branded versions of the medication and the lowest willingness (47\%) was seen among the participants who would prefer not to register their real name for the medication order. Lower acceptability of receiving contraceptive pills by post was observed among participants who were: above the age of 45 years and those who expressed a preference for a consultation with a pharmacist to discuss side effects and dosage. Higher acceptability was reported by women who had collected medication at a pharmacy in the past and who were willing to complete an online questionnaire about their health before ordering medication.

\section{DISCUSSION}

To our knowledge, this is the first study exploring the acceptability and user preferences for remote prescribing and postal treatment for chlamydia treatment and contraception provision. The findings indicate that most participants would agree to provide the necessary information for remote prescribing such as real name, medical and drug/allergy history and blood pressure readings. ${ }^{15} 16$ Although approximately only 1 in 12 participants had previously received medication in the post, the majority reported 'medication by post' or 'click and collect' as their preferred delivery methods. This suggests that a significant proportion of service users would be receptive to remote antibiotic treatment and contraception services, as the preferences overlap with acceptability, indicating a willingness to receive medication away from the clinic. Most participants were willing to receive generic drugs and would expect delivery within three working days or, in the case of chlamydia treatment, next day delivery. Sexual health clinics were the preferred source of information about 'medication by post'.

Previous studies have demonstrated the value of assessing acceptability and motivations for digital services. One study indicated mixed attitudes towards remote prescribing services among health professionals, with perceived usefulness, ease of use and perceived risk of error in prescribing associated with acceptability. ${ }^{17} \mathrm{~A}$ small study of medication by post in Malaysia showed that service users were unaware of this method of delivery and only a half showed interest 
Table 2 Sample characteristics and preferences for e-prescribing $(n=1281)$

\begin{tabular}{|c|c|c|c|}
\hline Variable & Total (n (\%)) & Variable & Total (n (\%)) \\
\hline Demographic variables & & Preferences for remote prescribing and postal treatment & \\
\hline Age (years) & & Willingness to receive antibiotic by post & \\
\hline$<18$ & $41(3)$ & Yes & $1042(82)$ \\
\hline $18-24$ & $555(46)$ & No/not sure & $230(18)$ \\
\hline $25-34$ & $410(34)$ & Willingness to receive contraceptive pills by post & \\
\hline $35-44$ & $122(10)$ & Yes & $797(83)$ \\
\hline $45-54$ & $56(7)$ & No/not sure & $160(17)$ \\
\hline $55-64$ & $22(2)$ & Willingness to provide blood pressure reading & \\
\hline$>65$ & $7(<1)$ & Yes & $772(81)$ \\
\hline Gender & & No/not sure & $185(19)$ \\
\hline Male & $325(26)$ & Willingness to receive generic contraceptive pills & \\
\hline Female & $932(74)$ & Yes & $640(67)$ \\
\hline Non-binary & $3(<1)$ & No/not sure & $313(33)$ \\
\hline Other & $5(<1)$ & Concerned about confidentiality using postal delivery & \\
\hline Ethnicity & & Yes & $312(24)$ \\
\hline White & $1163(91)$ & No/not sure & $960(76)$ \\
\hline Black African & $22(2)$ & Concerned about delivery if absent at home & \\
\hline Black Caribbean & $11(1)$ & Yes & $554(44)$ \\
\hline Asian & $21(2)$ & No/not sure & $715(56)$ \\
\hline Mixed-race & $47(4)$ & Willingness to speak with health advisor via telephone prior to finalise medication ord & \\
\hline Other & $10(<1)$ & Yes & $1078(85)$ \\
\hline Sexual orientation & & No/not sure & $194(15)$ \\
\hline Heterosexual or straight & $1091(86)$ & Willingness to disclose pre-existing conditions & \\
\hline Gay or lesbian & $78(6)$ & Yes & $1053(89)$ \\
\hline Bisexual & $83(7)$ & No/not sure & $126(11)$ \\
\hline Prefer not to say and other & $17(1)$ & Willingness to register a real name for the order & \\
\hline Education & & Yes & $1075(85)$ \\
\hline No formal education & $91(7)$ & No/not sure & $191(15)$ \\
\hline Primary school & $8(<1)$ & Willingness to fill in an online questionnaire about health prior to medication order & \\
\hline High school & $144(12)$ & Yes & $987(78)$ \\
\hline Collage & $508(41)$ & No/not sure & $280(22)$ \\
\hline University degree & $473(38)$ & Preference for signed tracked delivery & \\
\hline Other & $24(2)$ & Yes & $443(35)$ \\
\hline Registered with GP & & No/not sure & $821(65)$ \\
\hline Yes & $1208(95)$ & Preference for a consultation with a pharmacist to discuss side effects and dosage & \\
\hline No/not sure & $66(5)$ & Yes & $345(27)$ \\
\hline Past STI diagnosis & & No/not sure & $918(73)$ \\
\hline Yes & $504(40)$ & Preference for mobile telephone updates about the delivery status & \\
\hline No & $729(57)$ & Yes & $1050(83)$ \\
\hline Not sure & $42(3)$ & No/not sure & $212(17)$ \\
\hline Frequency of STI screening & & Preferred waiting time for antibiotic to be delivered & \\
\hline First time & $249(20)$ & Next day delivery & $522(43)$ \\
\hline Once every few years & $379(30)$ & Within 3 working days & $524(43)$ \\
\hline Once a year & $266(22)$ & Within 5 working days & $148(12)$ \\
\hline Several times a year & $354(28)$ & Within 7 working days & $25(2)$ \\
\hline
\end{tabular}




\begin{tabular}{|c|c|c|c|}
\hline Variable & Total (n (\%)) & Variable & Total (n (\%)) \\
\hline Preferred method of STI screening & & Preferred waiting time for contraceptive pills to be delivered & \\
\hline Online (home) testing & $611(48)$ & Next day delivery & $337(37)$ \\
\hline At a sexual health clinic & $552(44)$ & Within 3 working days & $418(46)$ \\
\hline At GP surgery & $83(7)$ & Within 5 working days & $103(12)$ \\
\hline Other & $15(1)$ & Within 7 working days & $41(5)$ \\
\hline $\begin{array}{l}\text { Variables related to } \\
\text { medication delivery }\end{array}$ & & Optimal waiting time to contact the clinic in case the delivery is misplaced & \\
\hline $\begin{array}{l}\text { Ever collected medication at the } \\
\text { pharmacy }\end{array}$ & & 1 day & $451(36)$ \\
\hline Yes & $1104(87)$ & 2-3 days & $603(48)$ \\
\hline No/not sure & $171(13)$ & $4-7$ days & $168(14)$ \\
\hline Ever received medication via post & & Over a week & $32(2)$ \\
\hline Yes & $97(8)$ & Preferred source of advice on the medication delivered by post & \\
\hline No/not sure & $1179(92)$ & GP & $387(31)$ \\
\hline $\begin{array}{l}\text { Preference for receiving medication } \\
\text { (general) }\end{array}$ & & Sexual health clinic & $711(57)$ \\
\hline Delivered to home & $568(45)$ & Pharmacy & $126(10)$ \\
\hline Given by a doctor & $260(20)$ & Other & $29(2)$ \\
\hline Collected at pharmacy & $427(34)$ & & \\
\hline Other & $15(1)$ & & \\
\hline \multicolumn{4}{|l|}{$\begin{array}{l}\text { Preference for receiving chlamydia } \\
\text { treatment }\end{array}$} \\
\hline Delivered to home & $721(57)$ & & \\
\hline Given by a doctor at the clinic & $261(21)$ & & \\
\hline Collected at pharmacy & $273(22)$ & & \\
\hline Other & $9(<1)$ & & \\
\hline \multicolumn{4}{|l|}{$\begin{array}{l}\text { Preference for receiving } \\
\text { contraceptive pills }\end{array}$} \\
\hline Delivered to home & $536(60)$ & & \\
\hline Given by a doctor at the clinic & $92(10)$ & & \\
\hline Collected at pharmacy & $250(28)$ & & \\
\hline Other & $20(2)$ & & \\
\hline
\end{tabular}

in the service, with the majority reporting concerns with a potential missed delivery. ${ }^{18}$ In the present study, about $20 \%$ of participants were not willing to provide via an online questionnaire the information necessary to allow safe prescribing. Hence, users' concerns should be explored in more detail in subsequent research to identify common barriers and design usercentred digital services for all patients and identify those who find digital services less suitable. Although telemedicine offers valuable opportunities, there is a risk of widening health inequalities due to access to digital technologies. ${ }^{19}$ Thus, service users who are not capable or unwilling to use e-prescribing due to digital literacy, access to technology or personal preferences should have access to alternative pathways of care.
This study achieved a large sample size and provides novel knowledge about online services. However, there are several limitations as it was exploratory and not designed to test prespecified hypotheses. The participants were recruited within one NHS Trust in Hampshire and their responses may not be representative of service users in other regions, especially in big cities, and individuals that are 'seldom heard' or hard-to-engage. Due to various sources of recruitment, we were uncertain about the refusal rate and how that affected the representativeness of the sample. Also, the survey was conducted before the coronavirus outbreak and patients' views on remote prescribing and postal treatment might be different if assessed now. The novel coronavirus SARS-CoV-2 (COVID-19) outbreak 
in 2020 transferred the majority of SRHS either to telephone or online assessments, as face-to-face healthcare was dramatically reduced, due to social distancing measures and staff illness or redeployment. Remote management using telephone assessments and online services has allowed service provision to continue, including diagnosis and management of sexual health conditions with remote prescribing and postal treatment or 'click-and-collect'. These developments mean that the current findings are of particular importance as they provide insight into individuals' preferences before service changes are implemented and they will inform future service development as we transition from lockdown to a post-COVID-19 time.

In conclusion, as a majority of service users in this study were receptive to these methods of delivery, remote prescribing and postal delivery of treatment for uncomplicated chlamydia and contraception should be considered as part of SRHS. Nevertheless, such a service needs to be closely monitored to identify any potential missed delivery, medication non-adherence, or misuse. Further research needs to explore health professionals' and service users' concerns as well as individual barriers in order to design the most acceptable, effective and equitable digital SRH services supporting patients with their treatment and prophylaxis.

Twitter Cynthia Ann Graham @cygraham_graham

Contributors TN, YS and RC designed the study. All coauthors contributed to the analyses and the interpretation of findings as well as the drafting of the manuscript, and approved the final version of the manuscript.

Funding The authors have not declared a specific grant for this research from any funding agency in the public, commercial or not-for-profit sectors.

\section{Competing interests None declared.}

Patient and public involvement Patients and/or the public were not involved in the design, or conduct, or reporting, or dissemination plans of this research.

\section{Patient consent for publication Not required.}

Ethics approval Solent NHS Trust Service Research and Improvement.

Provenance and peer review Not commissioned; externally peer reviewed.

Data availability statement Data are available upon reasonable request. No additional data.

\section{ORCID iDs}

Tom Nadarzynski http://orcid.org/0000-0001-7010-5308 Cynthia Ann Graham http://orcid.org/0000-0002-7884-599X

\section{REFERENCES}

1 World Health Organization. Global health sector strategy on sexually transmitted infections 2016-2021, 2016. Available: http://www.who.int/

2 Public Health England. Sexually transmitted infections and screening for chlamydia in England, 2018. Health Protection Report 2019;13:19.

3 Development Economics. Unprotected nation: the financial and economic impacts of restricted contraceptive and sexual health services. London: Society of Sexual Health Advisors,
2013. Available: http://ssha.info/wp-content/uploads/ Unprotected-Nation.pdf

4 Bébéar C, de Barbeyrac B. Genital Chlamydia trachomatis infections. Clin Microbiol Infect 2009;15:4-10.

5 Cates W, Wasserheit JN. Genital chlamydial infections: epidemiology and reproductive sequelae. Am J Obstet Gynecol 1991;164:1771-81.

6 LaMontagne DS, Fenton KA, Randall S, et al. Establishing the National Chlamydia Screening Programme in England: results from the first full year of screening. Sex Transm Infect 2004;80:335-41.

7 Gkatzidou V, Hone K, Sutcliffe L, et al. User interface design for mobile-based sexual health interventions for young people: design recommendations from a qualitative study on an online Chlamydia clinical care pathway. BMC Med Inform Decis Mak 2015;15:72.

8 Turner K, Adams E, Grant A, et al. Costs and cost effectiveness of different strategies for chlamydia screening and partner notification: an economic and mathematical modelling study. BMJ 2011;342:c7250.

9 Wellings $\mathrm{K}$, Jones KG, Mercer $\mathrm{CH}$, et al. The prevalence of unplanned pregnancy and associated factors in Britain: findings from the Third National Survey of Sexual Attitudes and Lifestyles (Natsal-3). Lancet 2013;382:1807-16.

10 Guse K, Levine D, Martins S, et al. Interventions using new digital media to improve adolescent sexual health: a systematic review. J Adolesc Health 2012;51:535-43.

11 Salam RA, Faqqah A, Sajjad N, et al. Improving adolescent sexual and reproductive health: a systematic review of potential interventions. J Adolesc Health 2016;59:S11-28.

12 Estcourt CS, Gibbs J, Sutcliffe LJ, et al. The eSexual Health Clinic system for management, prevention, and control of sexually transmitted infections: exploratory studies in people testing for Chlamydia trachomatis. Lancet Public Health 2017;2:e182-90.

13 Aicken CRH, Sutcliffe LJ, Gibbs J, et al. Using the eSexual Health Clinic to access chlamydia treatment and care via the internet: a qualitative interview study. Sex Transm Infect 2018;94:241-7.

14 Gibbs J, Sutcliffe LJ, Gkatzidou V, et al. The eClinical care pathway framework: a novel structure for creation of online complex clinical care pathways and its application in the management of sexually transmitted infections. BMC Med Inform Decis Mak 2016;16:98.

15 General Medical Council. Remote prescribing via telephone, fax, video-link or online, 2012. Available: https://www.gmc-uk. org/ethical-guidance/ethical-guidance-for-doctors/prescribingand-managing-medicines-and-devices/remote-prescribing-viatelephone-video-link-or-online

16 Royal Pharmaceutical Society. Practical guide for independent prescribers, 2020. Available: https://www.rpharms.com/ resources/ultimate-guides-and-hubs/independent-prescribers

17 Omar A, Ellenius J, Lindemalm S. Evaluation of electronic prescribing decision support system at a tertiary care pediatric hospital: the user acceptance perspective. Information Technology and Communications in Health Conference Proceedings, 2017:256-61.

18 Lim B, Khan AR, Abidin NA, et al. Can 'Medication by Post' improve medication compliance? Australas Med J 2011;4:460.

19 Bol N, Helberger N, Weert JCM. Differences in mobile health app use: a source of new digital inequalities? The Information Society 2018;34:183-93. 